Territorios ajenos. El caso de la Cooperativa Agropecuaria de Presidencia Roque Sáenz Peña Limitada, Chaco. José Martín BAGENETA

Avances del Cesor, V. XIV, No 17, diciembre 2017, pp. 45-70.

ISSNe 2422-6580 / ISSN 1514-3899 - http://web2.rosario-conicet.gov.ar/ojs/index.php/AvancesCesor/index

\title{
Territorios ajenos. El caso de la Cooperativa Agropecuaria de Presidencia Roque Sáenz Peña Limitada, Chaco
}

\author{
Foreign territories. The case of the Limited Agricultural \\ Cooperative Presidencia Roque Sáenz Peña, Chaco
}

\author{
José Martin Bageneta \\ Consejo Nacional de Investigaciones Científicas y Técnicas \\ Centro de Estudios de Sociología del Trabajo \\ Facultad de Ciencias Económicas \\ Universidad de Buenos Aires \\ (Argentina) \\ bagemartin@gmail.com
}

\section{Resumen}

El artículo se propone describir y analizar las estrategias (socio-productivas) de la Cooperativa Agropecuaria de Presidencia Roque Sáenz Peña Ltda. (CARSP) a partir de sus acciones y representaciones ante las transformaciones socio-productivas agrarias acontecidas con el agronegocio en la provincia de Chaco. En una primera sección, se presenta la perspectiva teórica acerca del territorio, las organizaciones y el discurso que se aplica. En una segunda sección, se avanza en una breve historia de lo acontecido en el territorio chaqueño a partir del agronegocio y articula el recorrido regional con el reconocimiento de lo sucedido al conjunto del sector cooperativo agrario. En la tercera sección, se presenta y analiza el discurso del caso cooperativo frente a los cambios territoriales y sus estrategias.

Palabras Clave: Cooperativa agraria - Chaco - Agronegocio 


\begin{abstract}
This article aims to describe and analyze the socio-productive strategies of the Limited Agricultural Cooperative Presidencia Roque Sáenz Peña (CARSP) departing from their actions and representations facing the agricultural and socio-productive transformations brought by agri-business in the province of Chaco. The first section provides a theoretical perspective about territory, organizations and discourse. The second section is an historical report about the territory of Chaco during agribusiness, and the regional process is articulated with the process of the whole agricultural cooperative sector. The third section presents and analyzes the discourse of the cooperative case facing territorial changes and the strategies deployed.
\end{abstract}

Key Words: Agricultural Cooperative - Chaco - Agri-business

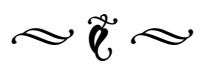

\section{Introducción}

"Como conclusión podemos decir a los productores que la politica de globalización es un desafio muy grande a superar y que solamente lo lograremos aunando esfuerzo y estando junto a la Institución que aun en las dificultades va defender los precios tanto de los insumos como de la producción."

"En éstas áreas marginales la continuidad de la actividad agrícola de pequeños y medianos productores en el corto plazo tendrán problemas de subsistencia." 2

Las cooperativas agrarias en tanto organizaciones insertas en sus sociedades manifiestan en su vida y devenir los acontecimientos sociales, productivos $y$ culturales del territorio. Ellas dan cuenta, por lo tanto, de relaciones históricas y procesos sociales. Los epígrafes elegidos son huellas discursivas de las tensiones propias de las organizaciones ante situaciones novedosas, cuando el territorio del agronegocio hace

1. CARSP, Memoria y Balance General, Chaco, 1997, p. 8. 2. Ídem, 2003, p. 7. peligrar la misma existencia de los productores y de las asociaciones tal cual se conforman a comienzos del siglo XX.

El objetivo de este artículo es describir y analizar las estrategias (socio-productivas) de la Cooperativa Agropecuaria de Presidencia Roque Sáenz Peña Ltda. (en adelante CARSP), a partir de sus acciones y representaciones, ante las transformaciones agrarias acontecidas con el avance del agronegocio en la provincia de Chaco desde fines de la década del 1990 (1990-2010).

La entidad se crea en 1925 por pequeños y medianos productores algodoneros de la localidad homónima y vinculado al auge de ese cultivo en la región centro y noroeste de la provincia. Desde mediados del siglo $\mathrm{XX}$, comienza a diversificar sus actividades de la mano de un lento proceso de cambio en la provincia e incorpora acopio y procesamiento de granos así como actividades de servicio al productor.

Hacia fines de la década de 1990, el algodón deja su lugar central frente a la soja y, a su vez, 
se evidencia la crisis y desaparición de parte de su base social. La CARSP, no obstante el impulso de proyectos alternativos durante la primera década del 2000 (biodiesel y alimento balanceado), mantiene dificultades de distinta índole. Su acopio representa el $2 \%$ del total de la soja que produce el Chaco en el 2010; mientras que entre 1999 y 2010 pasa del 7\% al $1 \%$ del total de algodón de la provincia. ${ }^{3}$

Durante la campaña 1990, en el Departamento Comandante Fernández -en el cual se radica la asociación- la superficie sembrada con el textil es de 46.300 ha. y en 2014, de 4.500 ha.; mientras que en el mismo lapso la oleaginosa pasa de 10.000 a 30.390 hectáreas. Esas cifras no señalan un proceso lineal sino un recorrido con marchas y contra-marchas, vaivenes y antecedentes históricos que permiten comprenderlo. También, esta transformación está motivada por el movimiento geográfico hacia la zona sudoeste de la provincia tras una nueva ampliación de la superficie de cultivo. ${ }^{4}$

La desregulación y descentralización de la economía, la modificación de las estrategias productivas y el surgimiento de nuevos actores sociales, son las características destacadas del nuevo modelo de acumulación que se inicia en los '70 y se consolida en la década de $1990 .{ }^{5}$

3. Datos del Ministerio de Agroindustria Presidencia de la Nación- Sistema Integrado de Información Agropecuaria (MAGYP-SIIA).

4. BAGENETA, José Martín, Del algodón a la soja. Territorio, actores y cooperativas en el Gran Chaco Argentino (1960-2010), Intercoop, Buenos Aires, 2015.

5. BARSKY, Osvaldo y GELMAN, Jorge, Historia del agro argentino. Desde la conquista hasta fines del siglo XX, Mondadori, Buenos Aires, 2001; LATTUADA, Mario, Acción Colectiva y corporaciones agrarias en la Argentina. Transformaciones institucionales a los fines del siglo $X X$, Editorial Universidad Nacional de Quilmes, Bernal, 2006.
En este contexto priman, entre otros factores, las inversiones de capital y la incorporación de tecnología como parte de la polarización; el agro argentino se adapta al negocio. ${ }^{6}$

El desarrollo del proceso organizacional (y sus estrategias) es estudiado inserto en un proceso dialógico con el territorio como espacio apropiado y en disputa entre lógicas productivas $^{7}$ mientras que esa relación configura posibles alternativas a partir de normas, valores y principios cooperativos. ${ }^{8}$

Ante la nueva configuración que atraviesa el territorio del agronegocio y las consecuentes tensiones para el cooperativismo este artículo se pregunta: ¿cuáles fueron las acciones y discursos de la CARSP? ¿la entidad traza una estrategia ante los nuevos desafíos? La hipótesis que se sostiene es que si bien la entidad diversifica sus actividades, no logra estructurar una estrategia que le permita afrontar las características del agronegocio, tensionada por la realidad de su base societaria y el vínculo estructural con la debilidad del ciclo algodonero.

6. GRAS, Carla y HERNÁNDEZ, Valeria, El agro como negocio: producción, sociedad y territorios en la globalización, Biblos, Buenos Aires, 2013; GIRBAL-BLACHA, Noemí, "El poder de la tierra en la Argentina. De la cultura agrícola al agronegocio", en Estudios Rurales, Bernal, 2013, No 4, pp. 103-115.

7. FERNANDES, Bernardo, "Sobre a tipologia de territórios”, en SAQUET, Marcos Aurelio y SAVÉRIO SPOSITO, Eliseu (organizadores) Territórios e territorialidades: teorias, processos e conflitos, UNESP, São Paulo, 2008, pp. 197-215.

8. SCOTT, Richard, Institutions and Organizations. Ideas, Interests and Identities, Thousand Oaks, Sage,1995. (traducción propia del inglés); LATTUADA, Mario, Acción Colectiva..., Op. Cit. 
En este estudio se opta por una articulación propia de la triangulación metodológica. Por un lado, se da cuenta del análisis crítico de fuentes documentales de la propia asociación (Memorias y Balances anuales del período de estudio); a lo cual se agrega el acceso al mismo tipo de documentos de cooperativas de la zona -con una historia de cercanía-, así como de la cooperativa de segundo grado de la cual la CARSP es parte, la Unión de Cooperativas Agrícolas Algodoneras Ltda. (en adelante UCAL). Además de este corpus de datos primarios, se cuenta con entrevistas realizadas a productores asociados, dirigentes y personal de esta institución entre los años 2014 y 2015; ${ }^{9}$ así como entrevistas a miembros de los Consejos de Administración tanto del caso particular, como de su entidad de segundo grado. Finalmente, se recurre a estadísticas del sector cooperativo de nivel provincial y nacional.

El artículo se estructura a partir de un primer apartado con la presentación de los conceptos desde los cuales se analiza el proceso histórico y -en particular- al actor cooperativo. En segundo lugar, se da cuenta de la historia socio-productiva en función de la comprensión del territorio en el cual actúa la CARSP. En tercer término, se considera el caso en cuestión, a través de describir su situación socio-económica y de utilizar ejes para reconocer su estrategia. Por último, se presenta una reflexión final sobre interpretaciones posibles a partir de los hilos que articulan el estudio: territorio, agronegocio y cooperativismo agrario.

9. Para la presentación de las palabras de los entrevistados y en el marco de la ética de la investigación se preservan las identidades, modificando los datos biográficos (como el nombre y localización) y elementos distintivos.

\section{Conceptos para considerar a la cooperativa, su discurso y estrategias: territorio y organizaciones}

Este trabajo procura ponderar el cruzamiento de un dilema clásico del estudio organizacional: la relación organizaciónambiente. Se recurre a una integración teórica que no cercene los campos de conocimiento e intenta articular los conceptos de territorio, agronegocio y organizaciones. ${ }^{10}$

E1 "territorio" transita usos diferentes desde su conceptualización a fines del siglo XIX. Como un fashion concept, se le aplican, desde campos como la geografía, la etología, la historia, la economía y otras ciencias sociales $\mathrm{y}$ humanas, ${ }^{11}$ definiciones que se ajustan $\mathrm{y}$ mutan de acuerdo a los tiempos.

En las últimas dos décadas, tiene un abanico de usos que, en muchos casos, poco precisan sobre su sentido y, por lo tanto, se impone cierta ambigüedad. Aquí se parte de la comprensión de que "el territorio" es un recorte del espacio, términos éstos que suelen intercambiarse sin criterio teórico. Robert Sack define, en los años '80, la territorialidad "como el intento por parte de un individuo o un grupo de afectar, influenciar o controlar a la gente, las cosas y las relaciones mediante la delimitación de un área y la determinación de

10. Sobre la "imaginación sociológica", en tanto articulación de campos disciplinares puede leerse: MILLS, Wright, La imaginación sociológica, Fondo de Cultura Económica, Buenos Aires, 2007.

11. FERNANDES, Bernardo, "Sobre a tipologia de territórios...”, Op. Cit.; REBORATTI, Carlos, “E1 territorio rural: ¿actor social o escenario?”, ponencia presentada en VJornadas de Investigación y Debate. Trabajo, propiedad y tecnología en la Argentina rural del siglo XX, Universidad Nacional de Quilmes, Bernal, 2008. 
un sistema de control sobre la misma, y esa área será llamada territorio". ${ }^{12}$

En este trabajo se comparte la perspectiva del territorio como espacio de gobernanza apropiado, "hecho cosa propia, en definitiva, el territorio es instituido por sujetos y grupos sociales que se afirman a través de él". ${ }^{13}$ En consecuencia, existen múltiples territorios según las acciones orientadas a controlar el espacio, "cada institución, organización, sujeto, construye su propio territorio y el contenido de su concepto y poder político para mantenerlo". ${ }^{14}$

La perspectiva crítica de este artículo considera al agronegocio como un modelo agrario apoyado sobre crecientes inversiones de capital tras la persecución -a través de tecnología y más productividad- de mayores rentabilidades. En ese sentido, constituye una práctica discursiva y de legitimidad mediante distintas instituciones. Tiene un grado importante de "externalidad" con respecto al agro pues influye en la toma de decisiones de sectores que actúan en otras esferas económicas (industrial y financiero, centralmente). En el plano de las consecuencias, se pueden considerar las siguientes: un proceso de concentración

12. SACK, Robert David, "Human Territoriality: a Theory", en Annals of the Association of American Geographers, Malden, 1983, V. 73, № 1, p. 5.

13. PORTO-GONÇALVES, Carlos Walter, "De saberes e de territórios: diversidade e emancipação a partir da experiência latino-americana”, en CECEÑA, Ana (coordinadora) De los saberes de la emancipación y de la dominación, Consejo Latinoamericano de Ciencias Sociales, Buenos Aires, 2008, p.42.

14. FERNANDES, Bernardo Mançano, "Territorios en disputa: campesinos y agrobusiness", Land Action Network, 2010, p.6. Disponible en: <http://www. landaction.org/IMG/pdf/Bernardo_halifax_esp.pdf>. económica, crisis social, la degradación de recursos naturales, la configuración de perfiles nacionales monoproductores y dependientes.

En el artículo se afirma que las cooperativas pueden, según su práctica, concepción y estrategia, ser medios para la construcción de territorios del agronegocio o territorios solidarios. Se reconocen, por lo tanto, distintas aproximaciones teóricas para abordar el vínculo entre territorio -social y natural- y las cooperativas agrarias. La sociología de las organizaciones tiene entre sus repertorios centrales de análisis los conceptos de organización, objetivos-tareas y ambiente, que permiten comprender la vida de estas entidades en relación interior-exterior, que supere la dualidad.

Un campo organizacional es una arena de conflicto así como de cooperación que connota la existencia de una comunidad que comparte un sistema de sentido común y cuyos participantes interactúan más frecuentemente entre sí que con los actores fuera del campo. Se afirma que "las instituciones muestran estabilidad y capacidad para dar sentido a los procesos puestos en movimiento por medio de elementos regulativos, normativos y culturales-cognitivos. Estos elementos son los ladrillos centrales de la estructura institucional, proveyéndole fibras elásticas que guían comportamientos y resisten cambios" ${ }^{15}$

Las estrategias son líneas generales para lograr un determinado fin en cada organización, de ellas se desprenden tácticas y acciones particulares, que no implican inevitablemente unidireccioanlidad. Representan, por lo tanto, la lectura de este actor social -resultado

15. SCOTT, Richard ,Institutions and Organizations..., Op. Cit., p. 57. 
de historia y contexto- ante determinadas situaciones. Una definición elemental -con la cual se acuerda- es que "la estrategia es la técnica al servicio del logro de un objetivo (individual o colectivo; privado o público; pacífico o bélico-militar)" ${ }^{16}$

En dicha dirección Mario Lattuada permite agregar al plano organizacional la lectura de tipologías para procesos históricos. El autor plantea que en el contexto de un régimen social de acumulación de apertura y desregulación de los años '90 - en el cual se conforman los rasgos del agronegocio- las cooperativas agrarias entran en una etapa de "organización institucional en mutación". Señala la posibilidad de analizar esa situación a partir de dos subtipos ideales: mutualista y empresarial.

El primer subtipo "promueve retomar con mayor vehemencia un acercamiento entre los principios cooperativos y las prácticas institucionales, enfatizando los principios de solidaridad y ayuda mutua, y la participación democrática. Se caracteriza por estrategias que contemplan con mayor intensidad los intereses de los asociados... En estas organizaciones, el grado de compromiso y eficiencia estaría exigido y, nuevamente puesto en función, por principios ideológicos que enfatizan la distinción entre las sociedades de personas, como las cooperativas, y las sociedades de capital o empresas". ${ }^{17}$

En el segundo subtipo "tienden a un modelo macrocooperativo con objetivos de introducir

16. BOBBIO, Norberto, MATTEUCCI, Nicola y GIANFRANCO, Pasquino, Diccionario de Politica, Editorial Siglo XXI, Buenos Aires, 2005, p. 578.

17. LATTUADA, Mario, Acción Colectiva ..., Op. Cit., pp. 166-167. fórmulas de gestión empresarial, en los que prevalecen los criterios de rentabilidad económica en detrimento de los de solidaridad. En estos casos, se busca reducir las diferencias entre las cooperativas y las empresas de capital, con el objetivo de superar las restricciones que le impedirían responder con mayor eficacia a los desafíos del nuevo contexto competitivo. Esto requiere la adopción de una mayor envergadura económica y complejidad institucional... Implica, también, operar con terceros no asociados, constituir empresas de capital privado...". ${ }^{18}$

También, en el plano teórico-metodológico se afirma que las palabras de un corpus textual (como las Memorias y Balances generales de la cooperativa) cargan con sentidos en tensión, entre lo explicitado y lo latente. Se considera el discurso como una práctica social que crea y recrea la vida colectiva, interactúa con las situaciones, las instituciones y la estructura social. ${ }^{19}$

En este estudio se presta particular atención a la constante disputa entre actores sociales a la hora de establecer una nominación de la realidad y, por lo tanto, por apropiarse de los significantes que la nombran, o sea por el sentido común. Así es como se comprende que las palabras de las organizaciones insertas en un medio/territorio en transformación dan cuenta de necesidades internas y externas. ${ }^{20}$

Estas distintas herramientas analíticas, articuladas, permiten abordar, por un lado, a

18. Ibídem.

19. CALSAMIGLIA BLANCAFORT, Helena y TUSÓN VALLS, Amparo, Las cosas del decir. Manual de análisis del discurso, Ariel, Barcelona, 2002.

20. BOURDIEU, Pierre, Cosas Dichas, Gedisa, Buenos Aires, 1998, p. 118. 
la cooperativa en tanto parte de un entramado territorial que -como tal- cuenta con disputas y apropiaciones. A su vez, por otro lado, avalan estudiar el rasgo organizacional sobre el que repercuten dichos acontecimientos, en tanto la estrategia se considera en tensión con valores, principios y contextos históricos particulares.

\section{Breve historia del proceso territorial chaqueño en clave cooperativa: del algodón a la soja (1990-2010)}

La provincia del Chaco, a lo largo del siglo $\mathrm{XX}$, pasa del ciclo forestal del quebracho (Schinopsis balansae) al algodonero. ${ }^{21}$ Desde la década de 1920, el textil deviene central en el modelo regional. En cada ciclo la provincia ocupa un lugar marginal en el marco de la hegemonía de los intereses de la región pampeana. ${ }^{22}$ Desde mediados del siglo, comienza la incertidumbre para este esquema socio-productivo, al tiempo que, en el plano político, el Chaco deja de ser Territorio Nacional y se provincializa en 1952.

Hacia fines del siglo XIX, comienzan a desarrollarse experiencias asociativas como respuesta de los colonos a los abusos de los

21. MIRANDA, Guido, Tres ciclos chaqueños, Editorial Librería La Paz, Resistencia, 2005.

22. BRUNIARD, Enrique, "El Gran Chaco Argentino.

Ensayo de interpretación geográfica”, en Revista Geográfica, Resistencia, 1978, No 4, pp. 38-61; GIBERTI, Horacio, "Las dos argentinas agropecuarias", en Realidad Económica, Buenos Aires, 1984, № 61, pp. 29-48;

GIRBAL-BLACHA, Noemí, "Inserción de una región marginal en la Argentina Agroexportadora. El Gran Chaco Argentino y la explotación forestal. 1895-1914", en Actas del Octavo Congreso Nacional y Regional de Historia Argentina, Academia Nacional de la Historia, Buenos Aires, 1998, pp. 297-314. intermediarios, tanto de ramos generales (comerciantes de bienes de primera necesidad y de la producción) como de los monopolios acopiadores. A su vez, estas organizaciones tienen una importancia significativa como medio socio cultural de pertenencia del gran número de inmigrantes que las conforman. ${ }^{23}$ El Estado nacional fomenta la producción algodonera y la organización de los colonos en asociaciones. Hay un proceso de desarrollo del movimiento cooperativo argentino durante estas décadas reflejado en la conformación de entidades de primer grado con peso en la región pampeana. En ese marco, durante 1934, nace la cooperativa de segundo grado UCAL en Presidencia Roque Sáenz Peña que agrupa a entidades de la región central chaqueña. Su primer presidente proviene de la CARSP, asociación que gravitará en roles de representación durante el siglo XX.

En la década de 1960, la aparición de la fibra sintética y los bajos precios del algodón arrastran a los productores a una coyuntura difícil que se manifiesta en los descensos de la producción (en toneladas de semillas y fibra). Estas transformaciones significan una de las más profundas crisis para la región. El crecimiento en el Chaco de la superficie dedicada al cultivo de girasol y sorgo en la década de 1980 por encima de la destinada al algodón -en 1981 y 1985 - da cuenta de este cambio y de la reacción de la franja de productores capitalizados que pueden

23. BECK, Hugo, "El cooperativismo agrario en el Chaco. Factor de crecimiento económico y de integración sociocultural", ponencia presentada en las Terceras Jornadas de Historia Económica, Montevideo, 2003; MOGLIA, Leandro, "El movimiento cooperativo agrícola en el Chaco entre los Gobiernos de Regulación y Planificación (1930-1955)", ponencia presentada en XXI Jornadas de Historia Económica, Universidad Nacional de Tres de Febrero, Caseros, 2008. 
reconvertirse. Algunos autores comienzan a utilizar el término de "pampeanización" de la provincia. $^{24}$

Por lo tanto, desde mediados del siglo XX, se dificulta la situación de los productores algodoneros de los países como Argentina que no cuentan con una política estatal de subsidios para las producciones primarias, lo cual se encadena con la desarticulación del mercado interno. ${ }^{25}$

Aparecen en estos años en el cooperativismo algodonero los "free rider", asociados que no entregan toda su producción, a los cuales las entidades destinan mensajes recurrentes en sus Memorias. Estos "free rider" eligen dar el algodón en bruto a las acopiadoras privadas pues éstas les pagan el total del valor de la venta en el momento de entrega. Lo cual da cuenta de que progresivamente se desarticulan ciertas prácticas consecuentes fundacionales. También, hay un "tímido" reconocimiento de parte de estas entidades de que el algodón es un monocultivo y que esto constituye un problema. ${ }^{26}$

24. BRUNIARD, Enrique, "La diagonal árida argentina: un límite climático real”, en Revista Geográfica, Resistencia, 1982, No 95, pp. 5-20.

25. En particular, la cadena algodonera queda constituida en dos grandes sectores: los productores primarios locales (con su diferenciación intra-sectorial) y la industria textil. Sin que se logre la radicación de toda la cadena en la región (dado que el procesamiento de la fibra se realizaba afuera), las posibilidades de que alguno de los dos sectores haga hegemónico un modelo, se torna muy compleja. Sobre este asunto puede leerse: ROFMAN, Alejandro, Las economias regionales. Luces y sombras de un ciclo de grandes transformaciones 1995-2007, Editorial Centro Cultural de la Cooperación y Universidad Nacional de Quilmes, Buenos Aires, 2013.

26. GUY, Donna, “El Rey algodón'. Los Estados Unidos, la Argentina y el desarrollo de la industria algodonera argentina”, en Mundo Agrario, La Plata, 2000, V. 1, No 1.
En este contexto de reconversión hacia finales de los años '60 y comienzos de los ’70, se produce un alto grado de conflictividad social en torno al modelo algodonero -y las economías regionales- que tiene entre una de sus manifestaciones el surgimiento de las Ligas Agrarias. ${ }^{27}$

Durante el Proceso de Reorganización Nacional (1976-1983) ante la apertura económica y los precios internacionales altos, la superficie sembrada para 1976/1977 es de 228.650 ha., mientras que en $1978 / 1979$ pasa a 444.450 ha. Sin embargo, en 1979, la combinación entre el retraso cambiario y los bajos precios externos genera una pérdida significativa de rentabilidad y endeudamiento que arrastra a los asociados de las cooperativas. Los límites crediticios llevan a que aquellas se encarguen del financiamiento de sus socios en lugar de capitalizar los excedentes o redistribuirlos, lo que implica endeudamiento. ${ }^{28}$ En 1984, hay un nuevo aporte del Estado nacional que condona deudas del sistema cooperativo chaqueño aunque sin lograr detener la crisis (ley 23.143).

Desde mediados de siglo junto con la caída del modelo de sustitución de importaciones la exportación e importación de algodón comienza a ser una posibilidad y la liberalización de los años '90 determina la generación de dos puntos extremos en el

27. FERRARA, Francisco, Que son las ligas agrarias. Historia y documentos de las organizaciones campesinas del Nordeste argentino, Editorial Siglo XXI, Buenos Aires, 1973.

28. OBSCHATKO, Edith, BASAÑES, Carlos y MARTINI, Guillermo, Las cooperativas agropecuarias en la República Argentina: diagnóstico y propuestas, Ministerio de Agricultura, Ganadería y Pesca de la Nación/ IICA, Argentina, 2011, p. 77. 
Gráfico No 1. Superficie sembrada con algodón y soja (en hectáreas). Chaco. 1990-2010.

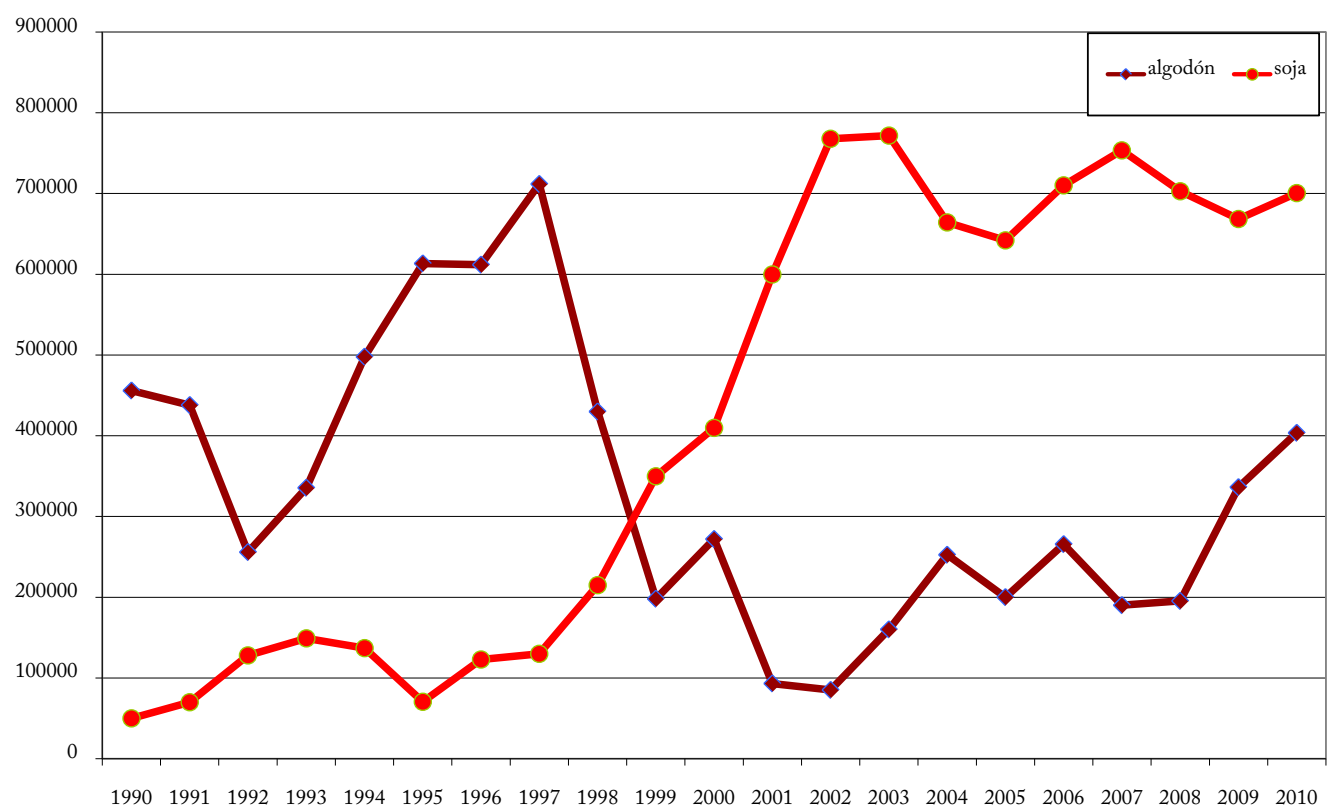

Fuente: Elaboración propia en base a datos del Sistema Integrado de Información Agropecuaria (MAGYP-SIIA, 2013) del Ministerio de Agricultura, Ganadería y Pesca (<http://www.siia.gov.ar/index. $\mathrm{php}>$ ).

sector algodonero (ver gráfico No 1). En 1995 hay un pico de producción y se concreta una exportación $^{29}$ histórica que tiene a Brasil como socio central y que para el año 1997 representa el 78\% del total de fibra exportada, lo cual implica una dependencia única que es un factor de debilidad para la matriz productiva. ${ }^{30}$ Por el contrario, durante los tres

29. La explosión de la superficie cosechada responde unilateralmente a los precios de la fibra a nivel internacional. En 1995 alcanza el record histórico de 100,76 dólares la tonelada, grupo B. Departamento de Agricultura de los Estados Unidos (USDA), 2011.

30. ROFMAN, Alejandro, Las economías regionales..., Op. Cit., p. 220. años siguientes, el descenso de los valores internacionales de la fibra desemboca en la caída más estrepitosa para el sector. Ante este comportamiento del precio mundial en "el caso de Argentina, fue singular el impacto pues la producción nacional carecía, entonces de toda estrategia reguladora que resguardase de los efectos de alteraciones muy significativas de las cotizaciones internacionales". ${ }^{31}$ Por lo tanto, desde la campaña de 1996 hasta el año 2000 se desciende en una vertiginosa pendiente. 
En relación a la estructura social agraria ${ }^{32}$ los Censos Nacionales Agropecuarios (en adelante, CNA) de 1969 y 2002 consignan desde mediados del siglo XX la importante presencia de pequeñas y medianas explotaciones y la ocupación de hecho. Entre 1969 y 2002, en la provincia desaparecen 12.005 explotaciones de hasta 100 hectáreas, que implica una reducción del $60 \%{ }^{33}$

El endeudamiento que arrastra el cooperativismo agrario desde la década anterior "condicionó sus posibilidades empresariales en un nuevo contexto macroeconómico y sectorial". ${ }^{34} \mathrm{Da}$ muestra de este proceso la participación en las exportaciones de fibra de las entidades sobre el total nacional, que pasa de 14, 4\% en 1992 a $7,1 \%$ en 1996. Otro dato en el mismo sentido es el desplazamiento del rol central en el desmote de algodón; entonces las cooperativas pasan del $42,7 \%$ en la campaña 1990 a un $27,8 \%$ en 2009 ; mientras que las desmotadoras privadas pasan del $57,3 \%$ al

32. Estructura social entendida como "Trama, retícula de las relaciones de interdependencia relativamente estables que existen en un conjunto determinado de posiciones sociales, papeles, instituciones, grupos, clases u otros componentes de la realidad social", en: GALLINO, Luciano, Diccionario de sociología, Editorial Siglo XXI, México, 1995, p. 410. En este caso se trata de las relaciones sociales agrarias consideradas como posiciones sociales que cambian o se mantienen en función de las pugnas de sectores y de los consecuentes cambios en la base económica. Los Censos Nacionales Agropecuarios son considerados una herramienta metodológica para poder considerar las características y conformación de la estructura social en el agro.

33. Instituto Nacional de Estadística y Censos (INDEC), Censo Nacional Agropecuario (CNA), 1969 y 2002.

34. OBSCHATKO, Edith, BASAÑES, Carlos y MARTINI, Guillermo, Las cooperativas agropecuarias..., Op. Cit., p. 77.

54
$72,3 \%$ para igual período ${ }^{35}$ (ver cuadro No 1 ).

Además, tienen un importante retroceso en el número de asociados, entidades y con las leyes de desregulación económica el cooperativismo pierde su carácter normativo. Los datos del Instituto Nacional de Economía Social y Asociativismo (INAES) reconocen que, desde el año 1991 hasta el 2010, se cancelan 21 organizaciones, 18 de ellas en el año 2001; paralelamente hay un proceso de creación de 10 cooperativas de nuevo tipo, en su mayoría a partir del 2003 y de la mano de políticas estatales que las promocionan. ${ }^{36}$

El cooperativismo agrario se encuentra ante los desafíos de sostenerse en la denominada economía de mercado. El auge de la globalización y la inestabilidad mundial dan un nuevo marco para su acción. Se acentúa el giro hacia perfiles cada vez más gerenciales. Un caso emblemático de estos cambios es el de la Asociación de Cooperativas Argentinas $(\mathrm{ACA})^{37}$ que durante este decenio se ajusta a "la pauta dominante en la economía nacional, adquirió participaciones en empresas privatizadas". ${ }^{38}$ Hay, a su vez, a nivel regional,

35. MINISTERIO DE PRODUCCIÓN DE LA PROVINCIA DEL CHACO, Estadisticas Algodoneras, Chaco, 2012, p.10.

36. INAES, Base de cooperativas a nivel nacional: mantenidas, suspendidas y canceladas, 31 de diciembre de 2013.

37. Los datos acerca de las exportaciones de granos desde la Argentina dan cuenta del crecimiento de la participación de dos asociaciones cooperativas, como ACA y Agricultores Federados Argentinos (AFA). Estas asociaciones representan juntas en 2012 el 11,70\% sobre el total de granos exportados, dentro de un eslabón con un alto grado de concentración.

38. LATTUADA, Mario y RENOLD, Juan Mauricio, El cooperativismo agrario ante la globalización, Editorial Siglo 


\begin{tabular}{llll}
\hline \multicolumn{3}{c}{ Cuadro 1. Desmote de algodón en cooperativas y empresas privadas } \\
(en toneladas). & Chaco. 1989-1996. \\
\hline Campaña & Des. Coop. & Des. Priv. & Tn. Total \\
\hline $1989 / 90$ & 210.671 & 250.453 & 461.124 \\
$1990 / 91$ & 200.080 & 268.246 & 468.326 \\
$1991 / 92$ & 125.540 & 212.998 & 338.538 \\
$1992 / 93$ & 49.900 & 144.025 & 193.925 \\
$1993 / 94$ & 121.674 & 256.152 & 377.826 \\
$1994 / 95$ & 124.704 & 433.349 & 558.053 \\
$1995 / 96$ & 167.712 & 522.507 & 690.219 \\
$1996 / 97$ & 105.885 & 439.954 & 545.839 \\
\hline
\end{tabular}

Fuente: Elaboración propia en base a: INTA Estación Experimental Sáenz Peña, Chaco (2000), Estudio de la cadena nacional agroindustrial algodón de la República Argentina, Secretaría de Agricultura, Ganadería, Pesca y Alimentación, Sáenz Peña, Chaco, octubre 2000.

experiencias cooperativas que se "adaptan" y consolidan su intervención a partir de "leer" las nuevas territorialidades del agronegocio y expandirse espacialmente en el acopio de soja y la venta de agroquímicos. ${ }^{39}$ Estas asociaciones, por lo tanto, están dentro de los rasgos que señala Mario Lattuada para los subtipos ideales empresariales.

Desde fines de los años “90, la "sojización” que reconfigura la "pampeanización" de las décadas anteriores es impulsada desde el modelo del agronegocio e implica cambios territoriales al poner en segundo lugar al textil y presentar una nueva inserción marginal. En 1990 en la provincia, la diferencia del algodón sobre la soja es de 406.000 ha. Mientras, que a partir de 1998, comienza un proceso de crecimiento

XXI, Buenos Aires, 2004, p. 30.

39. BAGENETA, José Martín, Del algodón a la soja..., Op. Cit. de la superficie sembrada con soja que tiene como punto de mayor distancia entre ambos cultivos el año 2002 cuando la brecha a favor de la soja es de 683.000 ha (ver gráfico No 1).

En el año 2010 se observa a nivel mundial que la producción algodonera -en base a un mayor rendimiento- supera el doble de lo alcanzado en 1965. El hecho se debe al aumento de aquella en los países "desarrollados" que brindan subsidios a este cultivo. ${ }^{40} \mathrm{~A}$ diferencia de la Argentina "en otras áreas productoras las estrategias de sustitución de importaciones incorporaron herramientas de aliento a la producción más allá de que el precio internacional no resultó un estímulo adecuado para tal decisión”. ${ }^{41}$

40. ROFMAN, Alejandro, Las economías regionales..., Op.

Cit., p. 219.

41. Ídem, p. 217. 
Durante el año 2000, la entidad que nuclea a las cooperativas agrícolas algodoneras, UCAL, se aleja de la Confederación Intercooperativa Agropecuaria (CONINAGRO) -a la cual regresa en los años siguientes- demostrando, una vez más, su retroceso en cuanto a la representación de los intereses sectoriales. En la Memoria del año 2002 se reconoce la parálisis institucional que acarrea desde tiempo atrás.

La situación de la deuda cooperativa -a la que se apela en reiteradas ocasiones- tiene un lugar central en el discurso y es un factor de presión y negociación para obtener del Estado -en sus diferentes niveles- condonaciones y "rescates" que pesan sobre el conjunto de la sociedad. También un estudio sobre el sector del Consejo Económico y Social de la provincia del Chaco (en adelante, CONES) ${ }^{42}$ junto a la UCAL refiere a que "las cooperativas están todas igual, embargadas o inhibidas. Pero son las únicas que hacen asistencia real a los productores, a pequeños y medianos productores reales, que aunque no sea tan buena como debiera, es asistencia real". ${ }^{43}$ Corrobora esta situación crítica el "Informe especial sobre las cooperativas agropecuarias algodoneras de la provincia del Chaco" realizado en el año 2003 por la Dirección de Cooperativas y Mutualidades de la provincia y el INAES. El documento recoge todos los datos contables y económicos-financieros

42. El Consejo Económico y Social de la Provincia del Chaco es un órgano constitucional de planificación estratégica, de carácter público no estatal, creado por Ley No 5081 del año 2002.

43. Consejo Económico y Social de la provincia del Chaco (CONES) y Unión de Cooperativas Algodoneras (UCAL). Cooperativas algodoneras chaqueñas: análisis económico, social y organizacional de sus factores internos y externos. CONES, Chaco, 2012, p. 17. de las entidades y afirma que "en términos generales, la situación es muy grave desde el punto de vista económico y financiero en casi todos los casos analizados". ${ }^{44}$

Finalmente el estudio del CONES aporta un importante material sobre las particularidades de los problemas que afronta este actor social debilitado frente al nuevo territorio, problemas con raíz histórica comprobada en distintas investigaciones y fuentes, así como en propio caso de la CARSP. La situación se puede sintetizar en los siguientes puntos: 1) Los asociados no entregan toda su producción y eligen dar gran parte a las acopiadoras privadas pues les pagan el total del valor de la venta en el momento de entrega, aunque el precio es menor al otorgado por la cooperativa. 2) El traslado de los puntos geográficos de producción algodonera al sudeste chaqueño, por lo cual las plantas desmotadoras de las cooperativas quedan lejos para su recepción. 3) Por estas razones y por la disminución y oscilación de la producción, la estructura productiva -trabajadores, maquinarias, desmotadoras- quedan sobredimensionadas $y$, por lo tanto, se producen déficits repetidos anualmente. 4) Las cooperativas terminan ocupando el lugar de financista de los socios y muchos no cancelan sus deudas, o lo hacen en última instancia, luego de cancelar otras acreencias. 5) La crisis de representatividad entre los dirigentes y la base de asociados, a lo cual se suma la falta de participación juvenil.

44. Dirección de Cooperativas y Mutualidades de la provincia e INAES, Informe especial sobre las cooperativas agropecuarias algodoneras de la provincia del Chaco, noviembre de 2003, p. 4. 
Mapa 1. Departamento Comandante Fernández, Chaco.

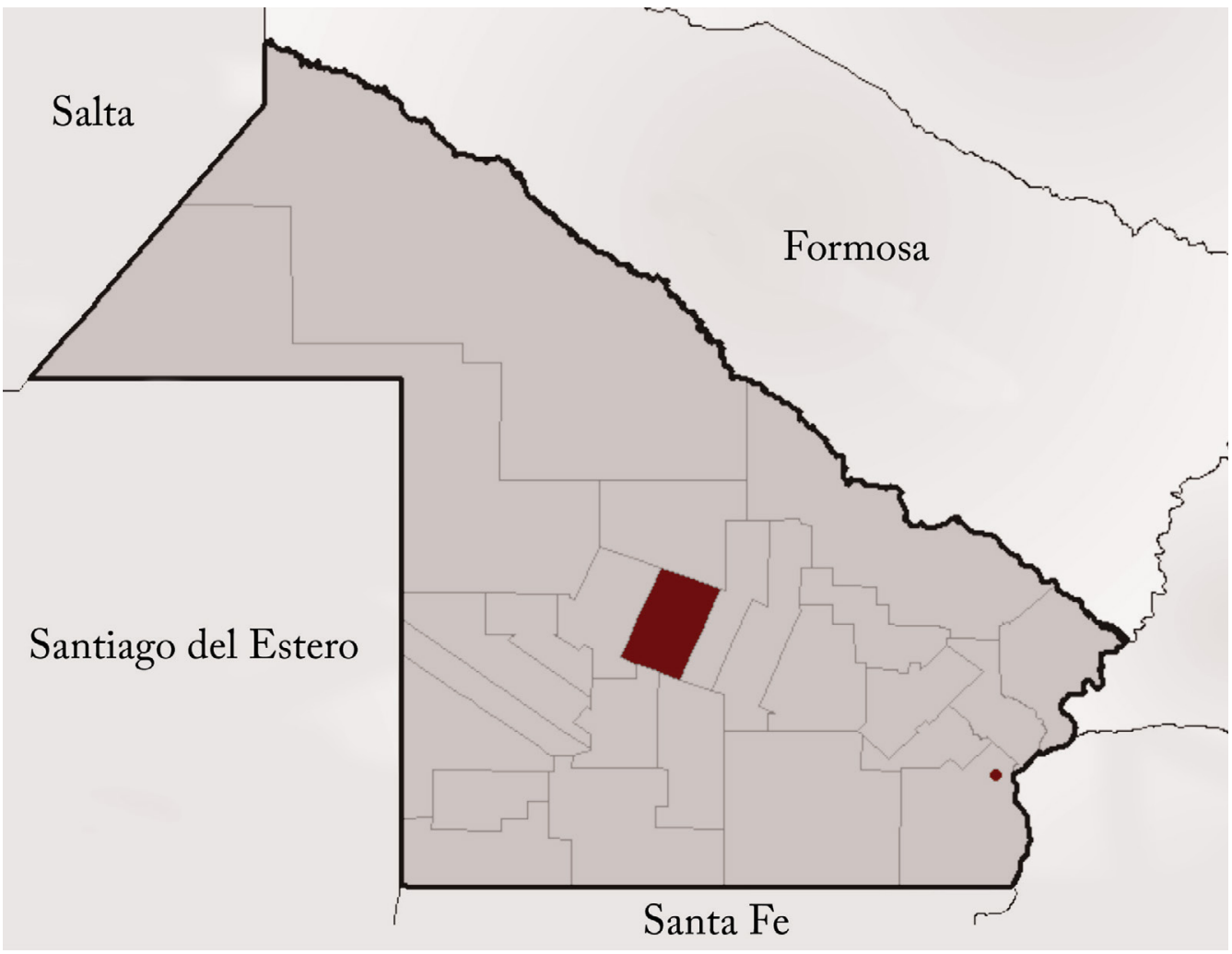

Fuente: <http://es.wikipedia.org/wiki/Departamento_Comandante_Fern\%C3\%A1ndez>.

La Cooperativa Agropecuaria de Presidencia Roque Sáenz Peña Ltda.

Caracterización histórica y socio-productiva de la organización

La CARSP nace el 11 de junio de 1925 en la localidad de nombre homónimo del Departamento Comandante Fernández. Tiene, al igual que múltiples entidades chaqueñas de comienzos del siglo XX, el influjo de la política estatal nacional que promociona su organización. Es de gran poder simbólico el hecho de que la primera reunión entre las múltiples propiciadas por el Ministro de Agricultura de la Nación, Tomás Le Bretón, se realice en la escuela No 31.

El algodón posee centralidad en su origen con una base social de pequeños y medianos productores. De hecho, su acción en las primeras décadas se dirige enteramente a ese cultivo. Por ejemplo, la Memoria y Balance General del año 1927, permite observar el carácter algodonero en sus secciones que 
son: "consideraciones generales", "algodón", "mercaderías", "comisión directiva" e "informe síndico". El textil remite al núcleo de su actividad.

En su estatuto, el artículo 5 sostiene como uno de sus objetivos, “a) Transformar, industrializar y vender todos los productos y sub-productos agropecuarios y forestales por cuenta de la Cooperativa y por cuenta de los asociados que reciban de la explotación propia o industrial...”. A su vez en su inciso "p" afirma una función analítica y de tipo estratégico "realizar estudios económicos y estadísticos permanentes, de la producción y de su costo a fin de orientar a los asociados en los cultivos apropiados para la zona, en base a la demanda en el mercado nacional e internacional y a una explotación diversificada y de rotación anual...". ${ }^{45}$

La CARSP tiene un rol activo en las entidades de representación de intereses. En 1934, el primer presidente de la UCAL proviene de la misma. En el plano representativo mantiene su adhesión a la Federación Agraria Argentina (FAA): "continuamos estrechamente ligados al accionar de este ente gremial, en lo que hace a la defensa de los derechos de nuestros productores, que muchas veces son despojados de sus derechos, por políticas erróneas". ${ }^{46}$

El Departamento Comandante Fernández ubicado en la región denominada -hacia mediados del siglo- como "domo algodonero" representa, en la década de 1970, un porcentaje importante de la superficie del textil -en 1970, el 16\%- sobre el total provincial, mientras que en la década de 1990 se corroboran cambios

45. Estatuto reformado de la CARSP, 1996, s/p.

46. CARSP, Memoria ..., Op. Cit., 1989, p. 20. territoriales. En ese sentido, se observa que hay un descenso relativo del peso de dicho territorio sobre la siembra provincial y la soja pasa de representar el 20\% en 1990 al 5\% en 2010 (ver gráfico № 2); mientras que el algodón desciende en esos años del $10 \%$ al $3 \%$. El proceso de expansión de la frontera agraria en el nuevo milenio se ubica sobre zonas provinciales del sudoeste $\mathrm{y}$, por lo tanto, pierde centralidad el departamento Fernández.

Raúl P. un alto dirigente de la CARSP y de la UCAL reflexiona en torno al proceso del agronegocio y el cambio en la localización, por lo tanto, en la territorialidad de la producción. Reconoce la expansión sobre otros espacios y demuestra la dinámica de ampliación de la frontera al afirmar que "los Bajos Submeridionales toda esa zona con el secado de los bajos, la canalización la gente sembraba soja, algodón cosa que antes no se hacía. Y bueno... esa es la novedad que últimamente estamos teniendo" ${ }^{47}$ Además, señala como una dificultad el hecho de que los asociados de la cooperativa se encuentren fuera de este proceso, "porque no tenemos productores de la zona que se hayan trasladado hacia esa zona $\mathrm{y}$ que son los cooperativistas antiguos que formaron todo este núcleo grande de UCAL y sus cooperativas [los que] se han quedado en la región. $Y$ algunos que se han divorciado si se quiere y se fueron hacia esa región están operando con los grandes grupos, ya no con UCAL". ${ }^{48}$

47. Entrevista a Raúl P., Sáenz Peña, realizada por José Martin Bageneta, en junio de 2010.

48. Entrevista a Raúl P., Sáenz Peña, realizada por José Martin Bageneta, en junio de 2010. 
Gráfico No 2. Superficie sembrada con algodón y soja en Dpto. Comandante Fernández sobre el total provincial (en porcentaje). AÑ OS: 1990, 2002 y 2010.

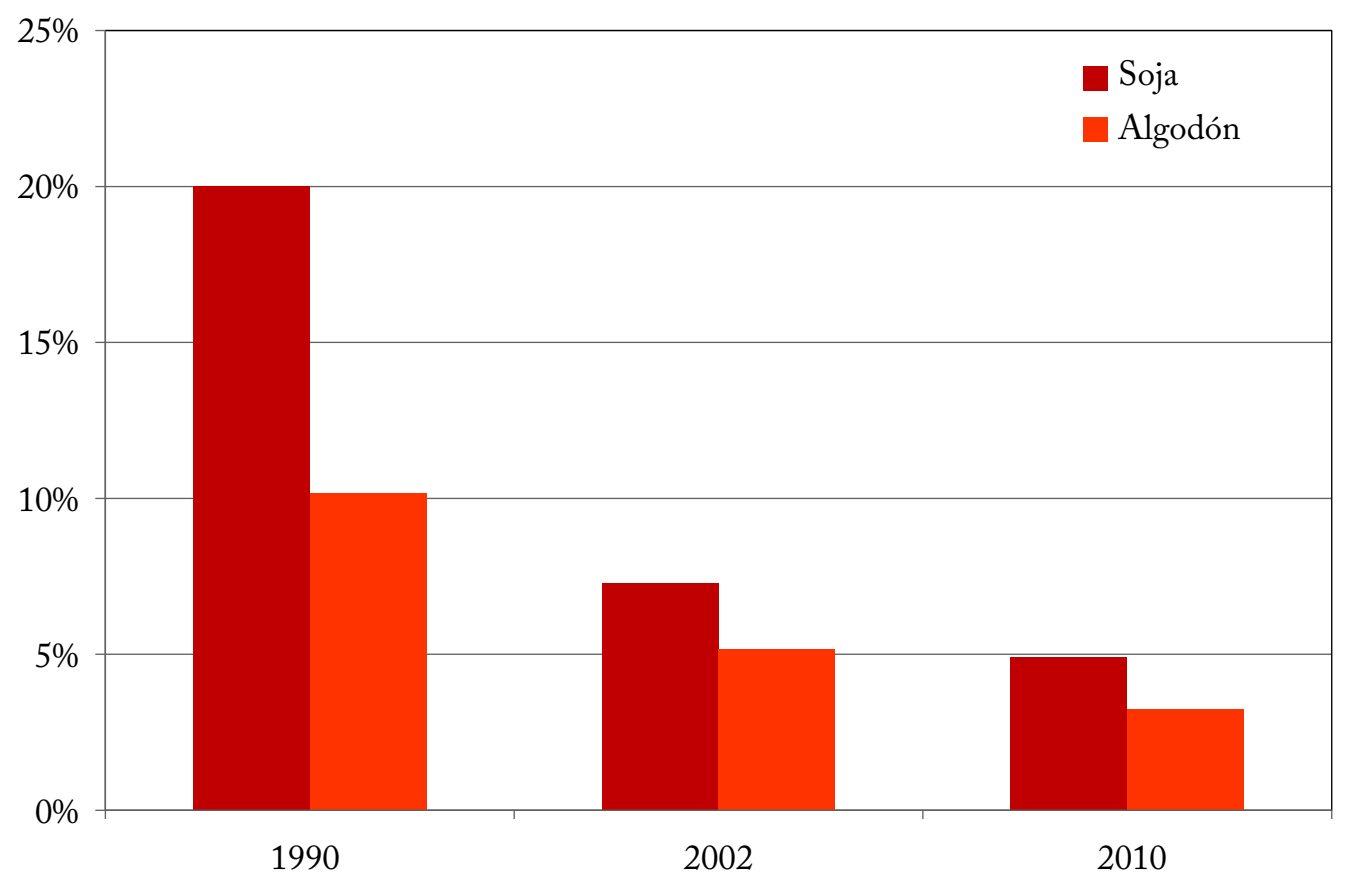

Fuente: Elaboración propia en base a datos del Sistema Integrado de Información Agropecuaria (MAGYP-SIIA, 2013) del Ministerio de Agricultura, Ganadería y Pesca (<http://www.siia.gov.ar/index.php/>).

La cantidad de socios tiene un significativo descenso luego de su pico histórico de 991 en 1961 . Así, en 1975 son 870 y, entre 1989 y 2011, se pasa de 484 a 222 (ver gráfico No 3). Esta merma evidencia las transformaciones que acontecen en el territorio y la estructura social agraria provincial con una importante disminución de pequeñas y medianas explotaciones. ${ }^{49}$

Comenzar la línea histórica relativa a la cantidad de asociados en el año 1975 aporta

49. CNA, 1969; 2002. a la comprensión del inicio de la caída, relacionándola con la incertidumbre del textil en la década de 1960 y el fuerte endeudamiento que se arrastra desde mediados de los '70 que condiciona a la organización hasta la actualidad.

En relación con el descenso de la masa societaria se registra en las memorias, desde mitad de los años '90, la incorporación de "clientes" no asociados en la búsqueda de adaptación a los tiempos del agronegocio que escapa al modelo cooperativo de tipo consecuente. En las Memorias hay apelaciones 
Gráfico No 3. Cantidad de asociados de la CARSP, 1975-2010.

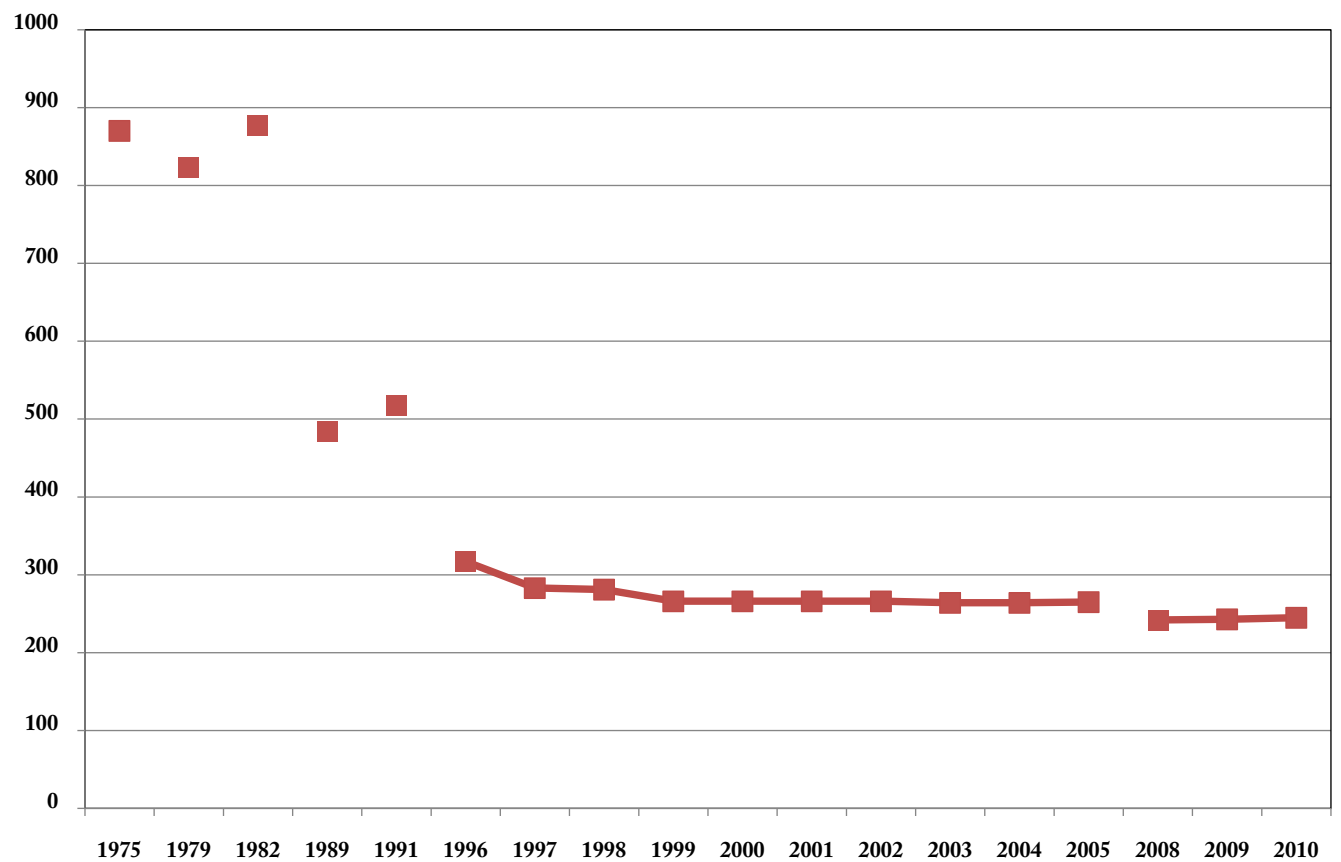

Fuente: Elaboración propia en base a: Memorias y Balances de CARSP (1975-2010).

directas a los productores "no socios", por ejemplo, en el año 2008 cuando se afirma que "se espera tanto de socios como productores no socios sepan acompañar a la cooperativa entregando toda la producción...". ${ }^{50}$ Esta denominación que se constituye en función de una negación (negación del "socio") demuestra intentos "adaptativos" y, a su vez, la primacía de las normas heredadas del momento de consecuencia con la entidad.

En una entrevista a Julio T., personal de la entidad con más de diez años de trabajo $\mathrm{y}$ con una relación permanente con los

50. Ídem, 2008, p. 13.

60 asociados, señala el peso de los clientes en la actualidad "hoy por hoy, el mayor volumen de la producción, la comercialización... de lo que es la evolución de la cooperativa es el tercero, son más los terceros que los socios. Como ya te digo, por ahí hay tipos que no son socios, que no tienen su parte dentro de la coope, pero si te operan en una medida importante y les brindamos el mismo servicio". ${ }^{51}$

En la cooperativa, al igual que otras asociaciones del agro regional, hay una referencia persistente a precios y clima. En sus Memorias son dos elementos de

51. Entrevista a Julio T., realizada por José Martin Bageneta, en junio de 2015. 
incertidumbre que refieren a los rasgos de la marginalidad, una socio-económica y otra de tipo espacial -en relación con la región pampeana-. ${ }^{52}$ Sobre estos planos que configuran el territorio, la organización articula discurso y estrategia. Por ejemplo, en la Memoria del año 1989 se manifiesta que "debemos destacar la respuesta favorable de parte del asociado, pese a las dificultades que se presentaban al principio de la campaña, debido a factores climáticos y económicos". ${ }^{53}$

En relación con el factor climático en una entrevista reciente a Jerónimo W., productor agropecuario con 100 ha, asociado con más de 25 años de membrecía y de familia cooperativista afirma que "lo que a nosotros nos maltrató muy mucho estas últimas, ponele, cinco campañas es el tema climático, los calores son muy fuertes y la falta de 1luvia". ${ }^{44}$

Desde mediados del siglo XX -con mayor importancia- comienza un lento proceso de incorporación de actividades. Por ejemplo, a la planta desmotadora con la que arranca en el año de su fundación agrega silos, fábrica de alimentos balanceados y veterinaria, transportes, estación de servicio, insumos agropecuarios, biodiesel y ferretería.

En este sentido, la sucesión de acciones e inversiones relativas a la estructura productiva expresan el cambio en el lugar del algodón e intentos de nuevas centralidades y estrategias. Las principales acciones de este tipo en orden

52. Para ampliar la información, puede leerse, entre otros: GIBERTI, Horacio, “Las dos argentinas...”, Op. Cit.

53. Ídem, 1989, p. 9.

54. Entrevista a Jerónimo W., realizada por José Martin Bageneta, en junio de 2015. cronológico son: 1) en 1999 se construye un nuevo silo de 500 toneladas (que se agrega a los construidos en 1974). 2) en 2001 se instala una planta de alimentos balanceados y 2 nuevos silos con capacidad de 750 tn. 3) en 2003 se terminan dos plantas de silos. 4) en 2004 se pone en funcionamiento de una segunda planta de alimento. 5) en 2005 se instala una planta de Extracción de Aceite Vegetal (con proyección hacia biodiesel). 6) en 2006 se construye la planta de Extrusado de Soja para la producción de Biodiesel y Expeller de soja para la planta de alimentos balanceados. 7) en 2007 se radica una fábrica de Biodiesel. 8) en 2009 se concluye la obra para carga de granos por ferrocarril, que finalmente no termina siendo operativa.

Las cantidades de cultivos acopiados por la cooperativa permiten reconocer el mismo camino de las acciones e inversiones. Se observa la diagonal inversa que trazan algodón y soja en sus tendencias lineales (ver gráfico No 4), en el mismo sentido de lo que sucede con la sojización a nivel provincial. Por un lado, el textil representa en 1989, con $17.639 .123 \mathrm{~kg}$., el $59 \%$ del total acopiado mientras que, en 2010 equivale al $7 \%$ con $4.919 .980 \mathrm{~kg}$.. Por otro lado, la soja pasa en igual lapso de representar el $12 \%$ con $3.609 .226 \mathrm{~kg}$. al $45 \%$ con $31.630 .950 \mathrm{~kg}$. Por último, el girasol sigue con un promedio de $13 \%$ en estos 14 años (ver gráfico No 4). Dentro de la categoría "otros" se encuentran el sorgo y el maíz, ambos con utilización -a partir de 2001- por parte de la CARSP para su planta de alimento balanceado.

Las fuentes permiten afirmar que los resultados económicos del período son negativos con la excepción de algunos años 
Gráfico No 4. Cantidad de algodón, soja, girasol, otros recibidos (en kilogramos) por la CARSP.

AÑOS: 1989, 1991, 1997-2005, 2008-2010.

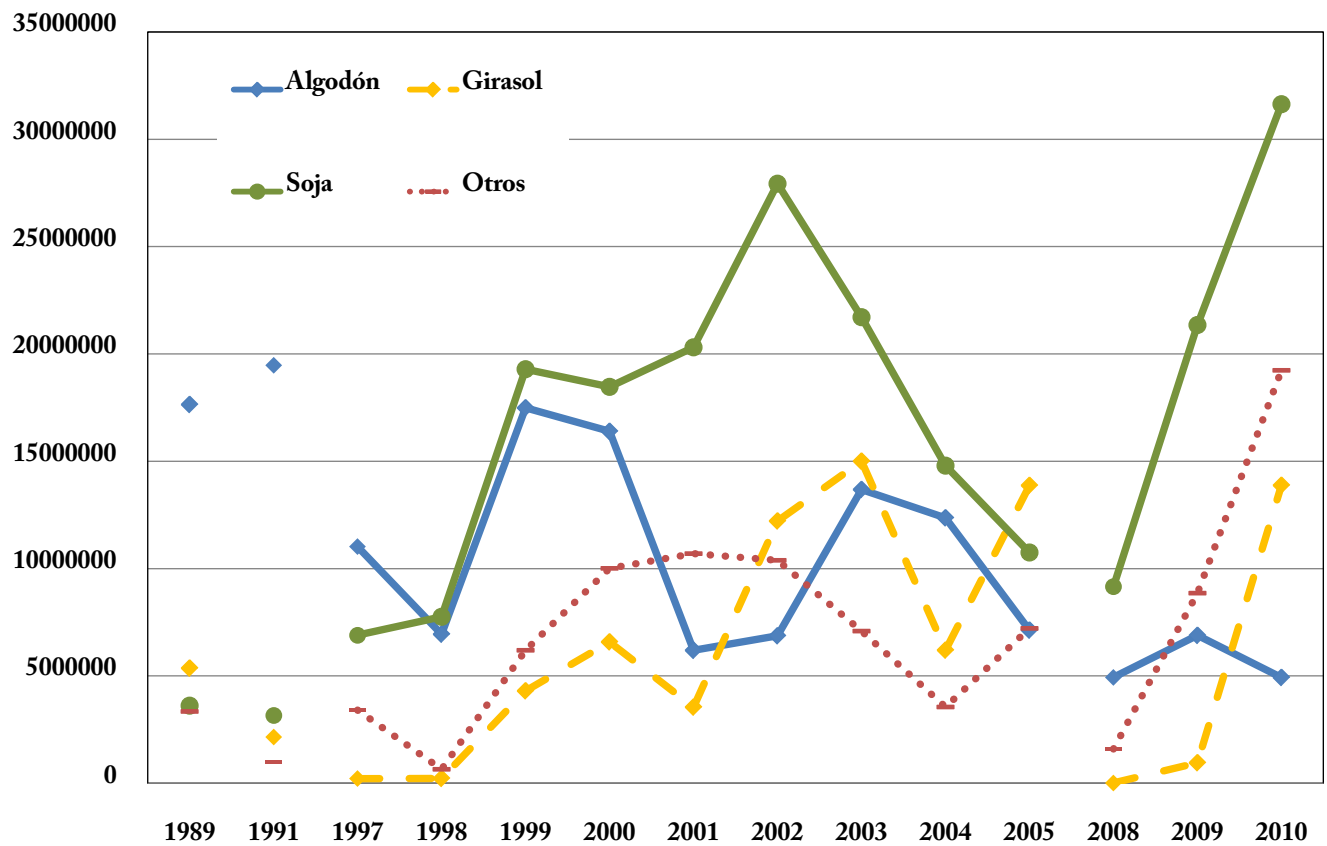

Fuente: Elaboración propia en base a: Memorias y Balances de CARSP (1989, 1991, 1997-2005, 2008-2010).

como 2001 y 2002. A su vez los informes de las auditorías dan cuenta de registros de deudas con el sistema previsional año tras año. En los balances contables se corrobora un resultado negativo de cada ejercicio: entre 2008 y 2015, cinco años son de signo negativo. Por su parte, el saldo del conjunto de estos ejercicios es de $-6540466,46$ pesos.

En mayo del año 2016, la cooperativa afirma que cierra la desmotadora, actividad que supo ser central desde su origen. Los consejeros informan como motivos, la disminución del volumen que acopian en relación a la estructura montada y los "desmedidos" pedidos de aumento salarial de los trabajadores. ${ }^{55}$

En el comportamiento y en el discurso de la CARSP se evidencia la dificultad propia de la incertidumbre que aporta la alternancia de ciclos de alto precio del algodón -o la expectativa de que lo sean-, con crecimientos de superficie directamente proporcionales y, otros momentos, de caída de su valor y/o el aumento del precio de los cultivos que pasan

55. SPNOTICIAS, Saenz Peña, 23/05/2016. Disponible en: <http://spnoticias.com.ar/2012-12-18-11-3909/5776-la-cooperativa-saenz-pena-cierra-sudesmotadora.html>. 
a ser competidores en superficie, como la soja -principalmente- y en menos medida el girasol.

Ejes transversales para considerar las estrategias de la entidad

A los fines de este artículo se opta por la utilización de dos ejes que permitan atravesar el período de estudio con la atención sobre la estrategia en función del discurso que la cooperativa sostiene ante el agronegocio. Este ejercicio analítico no niega que estas líneas temáticas se entrelazan. Los dos ejes son: la estructura productiva y el comportamiento de asociados/clientes y la situación financiera y la deuda.

El discurso de la cooperativa permite trazar una relación entre éstos dos ejes separados a los fines analíticos y expositivos. En aquel se percibe una centralidad sobre las acciones de los asociados que cruza las memorias de este período. Asimismo, se argumenta que la estructura productiva de la cooperativa queda "grande" por la no entrega del algodón, mientras que, a su vez, las finanzas tienen balances deficitarios no sólo por los aconteceres de índole climático y económico, sino por el incumplimiento de las deudas de parte de esa misma base social. La diversificación, aparece como la alternativa que la CARSP propone ante esos inconvenientes.

En el año 2008, la Memoria sintetiza dicho discurso con cariz estratégico que la entidad sostiene en el período: "En la actualidad la cooperativa para tener un futuro promisorio debe convertirse en un modelo de la actividad, para ello deberá tener una producción a escala, minimizar los costos mediante acuerdos con entidades, garantizar los créditos otorgados a los productores, beneficiar a los socios con el pago inmediato de la producción, obtener mayor beneficio con la comercialización en escala, para ello, se espera tanto de socios como productores no socios sepan acompañar a la cooperativa entregando toda la producción, adquiriendo en ella los insumos; siendo abiertos a nuevas modalidades de operatorias que puedan proponerse en el futuro". ${ }^{56}$

El estatuto de la CARSP así como sucede en las entidades de su tipo en la zona, en el inciso " $d$ " del artículo 11 , relativo a las obligaciones de los asociados, afirma como un deber el "operar con todos los productos de su explotación agropecuaria a través de la Cooperativa, siempre que ellos sean los que la Cooperativa reciba para su colocación en los distintos mercados". ${ }^{57}$

Esta norma de la organización se plasma en las Memorias y Balances. Como se señaló anteriormente, hay una significativa transformación en torno al peso de los productos que la cooperativa comercializa y de la acción consecuente de los asociados, lo que repercute en la estructura productiva de la entidad. Los valores relativos a las ventas de la CARSP evidencian estas mutaciones, el algodón representa en 1991, el 91\% y la soja el 6\%. En 2001, ésta última equivale al $44 \%$ y el textil, el 30\%. En estos años se corrobora que en promedio el $50 \%$ de las ventas corresponden al producto tradicional y el $28 \%$ para a la oleaginosa (ver cuadro No 2).

56. Ídem, 2008, p. 13.

57. Estatuto reformado de la CARSP, 1996, s/p. 


\section{Cuadro 2. Ventas por producción (en porcentaje) de la CARSP.}

1991, 1997-2005, 2008-2010.

\begin{tabular}{lcccccc}
\hline Ventas & $\mathbf{1 9 9 1}$ & $\mathbf{1 9 9 7}$ & $\mathbf{1 9 9 8}$ & $\mathbf{1 9 9 9}$ & $\mathbf{2 0 0 0}$ & $\mathbf{2 0 0 1}$ \\
\hline Algodón & 91,01 & $\mathbf{7 6 , 8 6}$ & 63,73 & 61,87 & 52,17 & 30,31 \\
Girasol & 2,55 & 0,51 & 1,08 & 6,13 & 9,33 & 8,56 \\
Sorgo & 0,09 & 0,17 & 0,15 & 0,44 & 1,04 & 2,84 \\
Trigo & 0,31 & 2,37 & 1,48 & 2,07 & 5,28 & 4,61 \\
Maiz & 0,18 & 1 & 0,57 & 1,39 & 2,04 & 2,8 \\
Cártamo & 0 & 0 & 0 & 0 & 0,07 & 0 \\
Colza & 0 & 0 & 0 & 0 & 0,01 & 0 \\
A. Balanceado & 0 & 0 & 0 & 0 & 4,46 & 6,5 \\
Soja & 5,87 & 19,08 & 32,98 & 28,09 & 25,6 & 44,38 \\
Total & $100 \%$ & $100 \%$ & $100 \%$ & $100 \%$ & $100 \%$ & $100 \%$ \\
\hline & & & & & & \\
\hline Ventas & 2002 & 2003 & 2004 & 2005 & 2008 & Promedio \\
\hline Algodón & 26,08 & 40,54 & 47,73 & 35,93 & 24,16 & 50,04 \\
Girasol & 22,56 & 22,12 & 13,23 & 28,48 & 25,46 & 12,73 \\
Sorgo & 0,2 & 0,66 & 0,14 & 0,4 & 1,78 & 0,72 \\
Trigo & 7,07 & 3,42 & 0,29 & 4,12 & 0 & 2,82 \\
Maiz & 1,18 & 0,78 & 1,39 & 0,43 & 2,42 & 1,29 \\
Cártamo & 0 & 0 & 0 & 0 & 0 & 0,01 \\
\hline Colza & 0 & 0 & 0 & 0 & 0 & 0 \\
A. Balanceado & 4,44 & 5,3 & 7,74 & 9,87 & 13,45 & 4,7 \\
\hline Soja & 38,48 & 27,18 & 29,49 & 20,77 & 32,74 & 27,7 \\
\hline Total & $100 \%$ & $100 \%$ & $100 \%$ & $100 \%$ & $100 \%$ & $100 \%$ \\
\hline & & & & & & \\
\hline & & & & 0 & 0 & 0 \\
\hline
\end{tabular}

Fuente: Elaboración propia en base a: Memorias y Balances de UAA (1991, 1997-2005, 2008-2010).

Se puede corroborar que esta cooperativa tiene durante el período la misma problemática de sus vecinas algodoneras, al sufrir una desarticulación significativa entre su estructura de acopio/procesamiento y la nueva realidad productiva. En particular, es deficitaria la cadena de procesamiento algodonera con las desmotadoras y los obreros que su funcionamiento implica, ${ }^{58} \mathrm{y}$, la parte dedicada a granos se readapta. En el

58. Hay en los informes de la auditoría realizados, año a año sobre el Balance de la CARSP, una constante presencia de la dificultad financiero debido a deudas respecto a aportes y contribuciones previsionales por remuneraciones del personal. 
análisis de las fuentes documentales se puede observar una situación pendular año a año, en relación directa con los precios y la superficie implantada con algodón y soja. Así, durante el período 1989-1991, el inconveniente más notorio es la necesidad de mayor capacidad de desmote, mientras que entre 1998 y 2002 es la propia estructura económica de la entidad la que es deficitaria (con excepción de 1999). Finalmente, luego de años de precios altos para los cultivos centrales, en 2005, 2008 y 2009 son negativas.

Ante esta situación, la entidad propone algunas estrategias. Por un lado, plantea aumentar la producción acopiada a fin de evitar la carencia para lo cual incentiva a los "socios entregadores" y a "terceros" a que sean leales con la CARSP. Por otro lado, apuesta a diversificar el peso de sus secciones para que una sola operatoria no redunde en el balance negativo del conjunto.

En relación con este pedido de "fidelidad" a la organización el asociado Jerónimo W. narra su percepción acerca de los motivos para comerciar una parte de su producción por fuera: "generalmente yo saco lo que es insumos de la cooperativa y le entrego prácticamente la producción a la cooperativa, se vende algo afuera, como quien dice, por el tema de la plata. A veces la cooperativa es un poquito más difícil el tema de la plata". ${ }^{59}$

En la Memoria del año 1997 se argumenta que la entidad peligra debido al déficit de sus resultados: "el futuro de la entidad depende de la posibilidad de utilizar su estructura productiva en el $100 \%$ y por consiguiente de la reciprocidad de sus asociados procediendo

59. Entrevista a Jerónimo W., realizada por José Martín Bageneta, en junio de 2015. a la entrega total de su producción cuando han sido atendidos con los insumos o se les refinanció sus deudas de arrastre". ${ }^{60}$

En 1999 se explicita la búsqueda de mayores dimensiones de acopio al incluir clientes en la comercialización y se lo valora positivamente en sus resultados: "la cooperativa también necesitada de un fortalecimiento ha recurrido a lograr los beneficios de la economía de escala, operando con productores que no son socios, de esta manera se ha visto incrementado el volumen acopiado de productos con relación a ejercicios anteriores, permitiendo absorber los costos fijos teniendo una incidencia proporcional menor para la producción". ${ }^{61}$

Durante 2001 se presentan los cambios territoriales del agronegocio y cómo afectan a la CARSP, "el espectacular vuelco producido del algodón hacia el cereal, motivó que el Consejo de Administración viera con preocupación la disminución en la explotación de nuestro equipo de desmotadoras que cuentan con un alto costo fijo (personal y otros)". ${ }^{62}$

En 2005 la organización reconoce las tensiones entre las líneas de acción que sostiene: "en la memoria del Ejercicio anterior que la alternativa consistía en ampliar sus ingresos con nuevas actividades... pero también decía que esto no sería suficiente, sino se comprende que la cooperativa es modelo de actividad productiva, donde la masa societaria y terceros encuentra un lugar adecuado para la comercialización de sus productos agropecuarios y acopios de los
60. Ídem, 1997, p. 13.
61. Ídem, 1999, p. 7.
62. Ídem, 2001, p. 8. 
insumos para la actividad en el campo, y por consiguiente deben ser consecuentes con la entidad". ${ }^{63}$

En relación al segundo eje transversal se constata que uno de los objetivos principales desde su nacimiento de las cooperativas algodoneras de la región, como la CARSP, es permitir el acceso a los insumos necesarios para la producción (centralmente semillas y combustible, luego agroquímicos). Esta situación se traduce en el rol de financiación de los productores que no tienen capacidad de capitalización propia. Por ejemplo, en 1989 se reconoce el cumplimiento de esa tarea, al afirmar que la Cooperativa proporciona importantes recursos "a la siembra de nuestros asociados, con entrega de semillas y herbicidas, tanto para la siembra de algodón como para soja, ampliando estos recursos, con un crédito por listado del Banco Nación Argentina". ${ }^{64}$

Juan Pablo F., personal de la cooperativa, en una entrevista reciente, reconoce la importancia de la entidad en un medio en el cual la financiación es cada vez más difícil. Enfatiza la diferencia entre los requisitos demandados por la entidad y los exigidos por el sector privado al afirmar que "acá vos venís y bueno - "tengo 100 hectáreas", nosotros vemos que están en condiciones y si no hablan mal de vos por ahí o no tenés VERAZ afectado o cualquier cosa, entonces se te da la oportunidad, si tenemos las condiciones, porque a veces nosotros no conseguimos ni la propia semilla para vender porque estamos tan ensartados". ${ }^{65}$

63. Ídem, 2005, p. 13.

64. Ídem, 1989, p. 10-11.

65. Entrevista a Juan Pablo F., realizada por José Martín 66
En el mismo sentido, Juan B. y Analía J. una pareja de productores con explotación agrícola de 110 ha. y que operan con la CARSP como clientes, reparan en la misma dualidad entre las empresas privadas y la cooperativa: "hoy inclusive a nosotros por ejemplo para entrar en una firma de esos, que tienen semillas, tienen todo, no nos van a dejar, nos van a pedir título del campo, nos van a pedir... hasta el libro de casamiento, qué se yo, no podemos entrar. Y por ejemplo acá nosotros entramos así, sin ningún problema". ${ }^{66}$

Como resultado del endeudamiento de los productores desde la década de 1970, con la tasa de interés negativa durante la dictadura, la asociación tiene créditos impagos de los asociados -con garantía de la entidad-. Desde comienzos de la década de 1990 tiene un nuevo ciclo de toma de deuda, principalmente con el Banco Nación Argentina, que se mantiene pendiente de cancelación en todo el período de estudio. Las Memorias y Balances generales permiten visualizar, año a año, este elemento con la creación de la sección "refinanciación deuda" -que se arrastra desde los años '80- destinada a reconocer la situación y sus avances/retrocesos.

De esta manera, se alegan en 2003 los motivos originales del crédito solicitado a comienzos de los años '90, "el objetivo por el que se obtuvo este crédito en los años 1990/1992 fue permitir que los productores siembren por la crisis que atravesaban. Esto se configuró en un crédito tipo planilla referencial donde

Bageneta, en junio de 2015.

66. Entrevista a Juan B. y Analía J., realizada por José Martín Bageneta, en junio de 2015. 
los productores recibieron el Crédito con la garantía de la cooperativa". ${ }^{67}$

La lectura de las fuentes documentales permite reconocer que esta situación de acreencia se extiende -en el discurso de la CARSP- desde el reconocimiento de la situación y el pedido a la base social de la cancelación de la misma hacia comienzos de la década de 1990 (cuando se toman los préstamos) hasta el intento por reconvertir ese pasivo a comienzos del nuevo milenio. En relación a esta última cuestión se arguyen distintas alternativas complementarias. Por un lado, se propone pedir refinanciación y, por otro, se insta a desconocer parte de la deuda por diferencias en el recálculo con la entidad bancaria. Finalmente, se solicita, asimismo, al gobierno nacional que se haga cargo de la deuda.

En relación al cierre de aquel tránsito, se recogen las palabras del ejercicio del año 2009 en el cual se afirma que "nuestro endeudamiento se encuentra en trámite en el Gobierno de la Provincia conforme al convenio con el Banco Nación, estimando que surgirá un importe inferior a lo declarado en el Estado Patrimonial o, en su defecto si se hace el re cálculo como lo presentamos al gobierno de la Pcia., de origen mas intereses del $9 \%$ anual, tenemos cancelada la deuda". ${ }^{68}$

\section{Conclusiones}

Estas páginas permiten unir dos posibles planos para un estudio que busca ceñirse al territorio: el nivel macro, al analizar el proceso

67. Ídem, 2003, p. 10.

68. Ídem, 2009, p. 8. para la región y el conjunto de las cooperativas agrarias y, el micro, al recurrir a la propia voz de la organización y sus integrantes. A su vez, las entrevistas y las Memorias permiten articular distintos discursos sobre procesos comunes dentro de la organización.

E1 Estado, tanto provincial como nacional, es una continuidad en tanto presencia central para las cooperativas algodoneras, devenidas agrícolas-ganaderas. En los documentos aparece considerado como garantía de concreción de los pasos tácticos de la estrategia; de modo que ante ciertas inversiones, o deudas se pide su socorro

En un rasgo que pareciera distintivo de la situación de las cooperativas de la región, la CARSP presenta capacidad para mantener estrategias de tipo ofensivo con respecto al modelo del agronegocio, entendiendo por "ofensivo" el intentar acciones que buscan responder a la nueva realidad. En cambio, gran número de entidades y la misma UCAL, muestran perspectivas defensivas que se asientan sobre una situación de dificultades económicas y financieras.

Aún, con dicha respuesta, la cooperativa no logra estructurar una estrategia ante el agronegocio, tensionada en la realidad de su base societaria y el vínculo con las debilidades arrastradas por el algodón.

En síntesis, la CARSP puede definirse como una "organización institucional en mutación" a partir de la categorización de Mario Lattuada y, a su vez, dentro de ella compartiendo características propias del subtipo ideal mutualista y el empresarial. Un ejemplo concreto es el hecho de que mientras se busca incorporar a "no asociados", 
en paralelo, se pide al conjunto de ellos, sin distinción de lazos, un accionar consecuente con la cooperativa.

$\propto \ddot{\varphi} \propto$

Recibido: 08-04-2016

Aceptado: 09-09-2016

Publicado: 05- 12-2017 


\section{Bibliografía}

BAGENETA, José Martín, Del algodón a la soja. Territorio, actores y cooperativas en el Gran Chaco Argentino (1960-2010), Intercoop, Buenos Aires, 2015.

BARSKY, Osvaldo y GELMAN, Jorge, Historia del agro argentino. Desde la conquista hasta fines del siglo XX, Mondadori, Buenos Aires, 2001.

BECK, Hugo, "El cooperativismo agrario en el Chaco. Factor de crecimiento económico y de integración sociocultural", ponencia presentada en Terceras Jornadas de Historia Económica, Montevideo, asociación Uruguaya de Historia Económica, 2003.

BOBBIO, Norberto, MATTEUCCI, Incola y GIANFRANCO, Pasquino, Diccionario de Politica, Editorial Siglo XXI, Buenos Aires, 2005.

BOURDIEU, Pierre, Cosas Dichas, Gedisa, Buenos Aires, 1998.

BRUNIARD, Enrique, "El Gran Chaco Argentino. Ensayo de interpretación geográfica”, en Revista Geográfica, Resistencia, 1978, No4, pp. 38-61.

BRUNIARD, Enrique, “La diagonal árida argentina: un límite climático real”, en Revista Geográfica, Resistencia, 1982, No 95, pp. 5-20.

CALSAMIGLIA BLANCAFORT, Helena y TUSÓN VALLS, Amparo, Las cosas del decir. Manual de análisis del discurso, Editorial Ariel, Barcelona, 2002.

FERNANDES, Bernardo, "Sobre a tipologia de territórios", en SAQUET, Marcos Aurelio y SAVÉRIO SPOSITO, Eliseu (Org.) Territórios e territorialidades: teorias, processos e conflitos, UNESP, São Paulo, 2008, pp. 197-215.

FERNANDES, Bernardo Mançano, Territorios en disputa: campesinos y agrobusiness, 2010, p.6. Disponible en: <http://www.landaction.org/IMG/pdf/Bernardo_halifax_esp.pdf>.

FERRARA, Francisco, Que son las ligas agrarias. Historia y documentos de las organizaciones campesinas del Nordeste argentino, Editorial Siglo XXI, Buenos Aires, 1973.

GALLINO, Luciano, Diccionario de sociología, Editorial Siglo XXI, México, 1995.

GIBERTI, Horacio, "Las dos argentinas agropecuarias", en Realidad Económica, Buenos Aires, 1984, № 61, pp. 29-48.

GIRBAL-BLACHA, Noemí, "El poder de la tierra en la Argentina. De la cultura agrícola al agronegocio", en Estudios Rurales, Bernal, 2013, No 4, pp. 103-115.

GIRBAL-BLACHA, Noemí, "Inserción de una región marginal en la Argentina Agroexportadora. E1 Gran Chaco Argentino y la explotación forestal. 1895-1914”, en Actas del Octavo Congreso Nacional y Regional de Historia Argentina, Academia Nacional de la Historia, Buenos Aires, 1998, pp. 297-314. 
GRAS, Carla y HERNÁNDEZ, Valeria, El agro como negocio: producción, sociedad y territorios en la globalización, Biblos, Buenos Aires, 2013.

GUY,Donna, ““E1 Rey algodón”. Los Estados Unidos, la Argentina y el desarrollo de la industria algodonera argentina”, en Mundo Agrario, La Plata, 2000, V. I, No 1.

LATTUADA, Mario y RENOLD, Juan Mauricio, El cooperativismo agrario ante la globalización, Editorial Siglo XXI, Buenos Aires, 2004.

LATTUADA, Mario, Acción Colectiva y corporaciones agrarias en la Argentina. Transformaciones institucionales a los fines del siglo XX, Editorial Universidad Nacional de Quilmes, Bernal, 2006.

MIRANDA, Guido, Tres ciclos chaqueños, Editorial Librería La Paz, Resistencia, 2005.

MILLS, Wright, La imaginación sociológica, Fondo de Cultura Económica, Buenos Aires, 2007.

MOGLIA, Leandro, "El movimiento cooperativo agrícola en el Chaco entre los Gobiernos de Regulación y Planificación (1930-1955)”, ponencia presentada en XXI Jornadas de historia económica, Universidad Nacional de Tres de Febrero, Caseros, 2008.

OBSCHATKO, Edith, BASAÑES, Carlos y MARTINI, Guillermo, Las cooperativas agropecuarias en la República Argentina: diagnóstico y propuestas, Ministerio de Agricultura, Ganadería y Pesca de la Nación/ IICA, Buenos Aires, 2011.

PORTO-GONÇALVES, Carlos Walter, De saberes e de territórios: diversidade e emancipação a partir da experiência latino-americana, en CECEÑA, Ana (coordinadora) De los saberes de la emancipación y de la dominación, Consejo Latinoamericano de Ciencias Sociales, Buenos Aires, 2008.

REBORATTI, Carlos, "El territorio rural: actor social o escenario?", ponencia presentada en $V$ Jornadas de Investigación y Debate. Trabajo, propiedad y tecnología en la Argentina rural del siglo XX, Universidad Nacional de Quilmes, Bernal, 2008.

ROFMAN, Alejandro, Las economías regionales. Luces y sombras de un ciclo de grandes transformaciones 19952007, Editorial Centro Cultural de la Cooperación y Universidad Nacional de Quilmes, Buenos Aires, 2013.

SACK, Robert David, "Human Territoriality: a Theory", en Annals of the Association of American Geographers, Malden, 1983, V.73, No 1, pp. 55-74.

SCOTT, Richard, Institutions and Organizations. Ideas, Interests and Identities, Thousand Oaks, Sage, 1995. 